\title{
LA IDEA DE UNA AUTORIDAD POLÍTICA MUNDIAL. CONSIDERACIONES CRÍTICAS A LA LUZ DE LAS EXIGENCIAS DE LA REALIDAD POLÍTICA
}

\author{
Sergio Raúl CASTAÑo \\ Director del Departamento de Política \\ Fundación Bariloche/CONICET \\ Profesor titular de Teoría del Estado \\ Facultad de CC. Jurídicas y Políticas (UNSTA) \\ sergioraulcastano@gmail.com
}

\section{RESUMEN}

A partir de los fundamentos del orden político-jurídico y de las aporías señaladas por la teoría del Estado y de las relaciones internacionales contemporáneas, buscando sustraerse a todo dogmatismo ideológico, el trabajo discute los argumentos axiales que han servido para sustentar la idea de un poder político mundial y señala los principales defectos de legitimidad que es dable descubrir en tal idea — sin detenerse en una propuesta particular de entre las varias y significativas que ban surgido a lo largo de los últimos siglos en sede teológica, filosófica, política y jurídica-.

Palabras clave: poder político mundial, seguridad, subsidiariedad, legitimidad política, derechos humanos, fin común.

\section{ABSTRACT}

From the fundamentals of legal and political order and from the aporias appearing in the Theory of State and contemporary International Relations, this article, renouncing all ideological dogmatism, criticizes the axial statements making the basis for the idea of a global political power and points at the main flaws of legitimacy which are likely to result from such idea by choosing no particular proposal among the significant abundant ones arising in the past centuries within theological, philosophical, political and legal domains.

Keywords: Global political power, security, subsidiarity, political legitimacy, human rights, common end.

\section{ZUSAMMENFASSUNG}

Von den Grundlagen der politisch-juristischen Ordnung und den Aporien ausgehend, die heute sowobl von der Staatstheorie als auch von der Theorie der internationalen Beziebungen hervorgeboben worden sind und in der Absicht, sich auf 
jeden ideologischen Dogmatismus zu enthalten, stellt der vorliegende Beitrag die grundsätzlichen Argumente, die dazu gedient baben, die Idee einer politischen Weltmacht zu unterstützen, in Frage, und weist auf die grundlegenden legitimatorischen Mängel hin, die in dieser Idee entdeckt werden können, obne sich bei einem besonderen Vorschlag, unter den verschiedenen und bedeutenden, die im Laufe der letzten Jabrbunderte in theologischen, philosophischen, politischen und juristischen Bereiche hervorgetreten sind, aufzubalten.

Schlüsselwörter: Politische Weltmacht, Sicherheit, Subsidiarität, politische Legitimität, politische Rechtmäßigkeit, Menschenrechte, Gemeinzweck.

SUMARIO: I. PRESUPUESTOS Y PRENOTANDOS-1. Esencia y principales propiedades de la potestad política.-2. La cuestión que nos ocupará.-II. LA AUTORIDAD MUNDIAL Y SUS CONFLICTIVAS APORÍAS.-1. El valor seguridad como tarea del poder mundial: presupuestos y consecuencias. La cuestión de la guerra.-a) Los presupuestos. La negación del carácter directivo del poder social y político._-b) La implicación de la seguridad en todos los ámbitos de la vida política. $\_$) La autoridad mundial y la evitación de la guerra.-2. La protección de derechos fundamentales (persona humana, grupos sociales) como materia de necesaria interpretación del ápice del poder.-3. Los criterios de legitimidad concreta monopolizados por una sola posición.-4. La «subsidiariedad» internacional y su ilícita analogía con el orden intraestatal.—a) Subsidiariedad, totalidad y politicidad.-b) Los principios que se inducen y se comprueban a partir de un fallo.-5. La estabilidad económica como inescindible de todas las dimensiones de la vida política y jurídica contenidas en el bien común.-III. UN INTENTO DE RESOLUCIÓN EN LOS PRINCIPIOS.-1. Heller: el Estado y su potestad soberana como causa y presupuesto del Derecho internacional.-2. La raíz ontológica y axiológica de la ilegitimidad política de una autoridad mundial.-a) El bien común internacional y los derechos del hombre.-b) La ilegitimidad de una subordinación sin integración. Y un cuestionamiento final.

\section{PRESUPUESTOS Y PRENOTANDOS}

\section{Esencia y principales propiedades de la potestad política}

En nuestro libro Lecturas críticas sobre el poder político arribamos a las siguientes conclusiones sobre la noción respectiva: «[L]a autoridad política constituye una función de naturaleza bipolar consistente en la dirección racional hacia el bien común político, necesaria e inderogable, presupuesta la existencia de una comunidad política, ejercida por titulares particulares, en la determinación de cuyos títulos de mando concurre el consenso de quienes obedecen. Se trata de una facultad directiva - dotada de atribuciones coactivas - cuyo modo propio de imperio es la jurisdictio y que 
se halla investida de supremacía normativa sobre todo otro poder (mundanal) en el ámbito de la comunidad política» ${ }^{1}$.

\section{La cuestión que nos ocupará}

Ahora bien, se plantea, se ha planteado y se planteará la cuestión de la viabilidad, necesidad, legitimidad de un poder (político) mundial. Nosotros, en lo que sigue, analizaremos algunos aspectos conflictivos de esa idea, entendida como la propuesta de un poder mundial a ser instaurado frente a un orden internacional cuyos sujetos, en principio, no hayan hecho renuncia explícita y formal a su status de unidades políticas. Pero sea como fuere, se hubiera producido o no semejante renuncia, en ningún caso sería válido dejar de asumir el dato insoslayable que la base empírica aporta a cualquier investigación sobre este tema: en efecto, se suponga o no la instauración previa de un Estado mundial, la experiencia muestra que los pueblos del orbe poseen y han poseído siempre una diversa configuración espiritual que aparece sedimentada en talantes, cosmovisiones y tradiciones también diversas, la cuales, a su vez, se traducen en disposiciones y ordenaciones socio-económico-jurídicas no menos diversas. A partir de ese dato empírico fundamental uno de los mayores politólogos del siglo Xx, Hans J. Morgenthau, «padre» de la teoría de las relaciones internacionales, cuando se cuestiona por la probabilidad de la creación de un Estado mundial responde que «en ningún periodo de la historia moderna las condiciones morales, sociales y políticas del mundo fueron menos favorables para el establecimiento de un Estado mundial. Tampoco se puede evitar, finalmente, la conclusión de que, del mismo modo en que no puede haber Estado sin una sociedad dispuesta y en condiciones de sostenerlo, tampoco puede haber Estado mundial sin una comunidad mundial dispuesta y en condiciones de sostenerlo» ${ }^{2}$.

En este examen polémico no nos ocuparemos de la viabilidad de un poder mundial, sino de su legitimidad (si bien un alto grado de ilegitimidad conspira contra la aparición o, por lo menos, la pervivencia fáctica de una institución). Discutiremos el problema a la luz de las exigencias fundamentales que se desprenden de la esencia de la autoridad política y del orden

${ }^{1}$ Cfr. S. R. Castaño, Lecturas críticas sobre el poder político, México, UNAM, 2013, pp. 239-240.

${ }^{2}$ H. J. Morgenthau, Política entre las naciones, trad. de H. W. Olivera, Buenos Aires, GEL, 1986, p. 586.

Foro, Nueva época, vol. 18, núm. 1 (2015): 27-60 
político. Discurriremos entonces entre el plano de los principios permanentes y el de la realidad empírica, entre el de la naturaleza de la cosa y su efectivización histórica; en las categorías jurídicas de la tradición clásica —que adoptaremos en estas líneas-, entre el derecho natural y el derecho positivo. Pues aunque nuestra dilucidación no desatenderá consideraciones histórico-particulares —antes bien, las supondrá en su tarea dialéctica一, con todo el siguiente análisis permanecerá dentro del plano de los principios y pretenderá valer como una objeción en ellos fundada y de validez universal.

\section{LA AUTORIDAD MUNDIAL Y SUS CONFLICTIVAS APORÍAS}

\section{El valor seguridad como tarea del poder mundial: presupuestos y consecuencias. La cuestión de la guerra}

Ha sido y es recurrente proponer la existencia de una instancia suprema de poder mundial que evite las guerras y los conflictos armados en general (inter- o intrastatales). En otros términos, la idea de un poder con recursos coactivos incontrastables, concentrado en un ápice, con facultades para intervenir en cualquier pare del globo - por la amenaza o el ejercicio de la fuerza - en defensa de la seguridad física y material de los hombres. La autoridad mundial fundaría así su justificación en el ejercicio de la coacción planetaria, teniendo en mira la tutela del valor seguridad ${ }^{3}$. Analicemos los presupuestos y las implicaciones de esta hipótesis.

\section{a) Los presupuestos. La negación del carácter directivo del poder social y político}

Ante todo, los presupuestos connotados por la idea así planteada. Debe señalarse que la función primaria de la potestad política no consiste en la organización de la coacción, lo cual implica que el objeto que especi-

3 Tal es la posición de H. KeLSEN, La paz por medio del derecho, trad. de L. Echávarri, rev. de G. Carrió, Buenos Aires, Losada, 1946, esp. p. 28. Esta idea, de cuño kantiano, fue replanteada más recientemente por el jurista L. FERRAJOLI, «La conquista de América y la doctrina de la soberanía exterior de los Estados», en R. Bergalli-Eligio Resta (ed.), Soberania: un principio que se derrumba, Barcelona, Paidós, 1996, pp. 171-172. Tampoco es ajena a esta perspectiva la concepción de autoridad mundial que anima la propuesta de la encíclica Pacem in Terris de Juan XXIII (1963) (cfr. su núm. 134). 
fica la facultad de imperio político no es la represión del mal moral y jurídico. En este tema clave vale la pena detenerse, pues no sólo echa luz sobre el sentido de la idea de un poder coactivo planetario, sino que constituye una cuestión fundamental de los saberes y de la realidad políticos.

Dos autores, un teólogo aristotélico y un clásico del marxismo, convergen en idéntica afirmación: la función de la autoridad social (y, a fortiori, política) consiste en la dirección de las conductas hacia un fin común, y la necesidad absoluta de la autoridad social y política no depende del mal moral ni de deficiencia humana alguna, sino de las exigencias objetivas de la cooperación y de la acción común. Se trata de Tomás de Aquino ${ }^{4}$ y de Friedrich Engels. Atendamos in extenso a la demostración del segundo, por demás significativa, como veremos.

Un especialista en la teoría marxista, discípulo, amigo y editor póstumo de Hermann Heller, Gerhardt Niemeyer, afirma con gracejo que si por «doctrina política» se entiende una teoría acerca de la naturaleza y la óptima eficiencia del Estado, el derecho y el gobierno, entonces no existe doctrina política marxista alguna. En efecto - continúa-, Estado, derecho y gobiernos son para el marxismo una suerte de enfermedad transitoria de la sociedad, aneja a su división en clases ${ }^{5}$. Tras la victoria final del comunismo (así lo dice, de hecho, Engels), el gobierno (Regierung) sobre las personas será reemplazado por la administración (Verwaltung) de las cosas y la dirección (Leitung) de los procesos de producción. Tan pronto como no haya que mantener una clase social en la opresión —sostiene el filósofo ale-

${ }^{4}$ Cfr. Suma Teológica, I. a , 96, 4 c. Literalmente, en latín, «utrum bomo in statu innocentiae homini dominabatur». Utilizamos la Editio altera Romana, t. I, Roma, Forzani, 1894, pp. 743-744. El valor de este paso para la filosofía política ya ha sido advertido por D. STERNBERGER, Herrschaft und Vereinbarung, Frankfurt am Main, Insel, 1980 (en la edición castellana Dominación y acuerdo, trad. de J. Seña, rev. de E. Garzón Valdés y R. Zimmerling, Barcelona, 1992, pp. 29 y ss.). El contexto teológico-dogmático del texto no es óbice a la intelección de su referencia a un orden social objetivo asequible a la razón. El término «dominio» (dominium), afirma Santo Tomás, también se aplica a la función de gobernar y dirigir a hombres libres. Alguien gobierna a otro como a un hombre libre en dos casos: cuando dirige al gobernado a su propio bien o cuando lo dirige al bien común. Ahora bien, esta forma de dominio se habría dado en el estado adánico de integridad moral (es decir, de pleno imperio de la justicia y de cordial amistad entre los hombres), pues la vida social no puede darse sin una instancia de dirección que ordene la pluralidad al bien común, dado que la multiplicidad, en cuanto tal, tiende a muchos fines, mientras que la unidad tiende a uno. De ahí que cuando muchos se ordenan a uno siempre se halla la presencia de un dirigente que dispone el orden a ese (fin) uno, afirma Tomás con cita de Aristóteles (Política, I).

5 G. NiEmeYer, «Politische Grundlehren des Kommunismus», en J. Bochenski y G. Niemeyer, Handbuch des Weltkommunismus, Freiburg-München, Karl Alber, 1958, pp. 75-76. 
mán-, tan pronto como la dominación de clase y la lucha por la existencia individual — fundada en la anarquía de la producción — sean elimidadas (beseitigen), entonces ya no quedará nada por reprimir que haga necesario un poder de represión, es decir, un Estado. Éste, pues, afirma Engels, no es «abolido» (abgeschaft), sino que se extingue (stirbt ab, subrayado original de Engels $)^{6}$. Ahora bien, es verdaderamente notable que sea el propio Engels quien - a pesar de la identificación que hace el marxismo del poder político con la opresión organizada-, al plantearse el estadio escatológico del fin de la historia, rescata y defiende el valor directivo y el sentido finalista de la autoridad social. En un breve pero importante artículo, «Von der Autorität», aparecido en el Almanacco Repubblicano per l'anno 1874, en italiano, en diciembre de 1873, Engels se propone refutar las tesis sobre el poder social de los anarquistas ${ }^{7}$. Algunos socialistas - refierehan lanzado una suerte de cruzada contra el llamado principio de autoridad (Autoritätsprinzip). De tal suerte, para condenar este o aquel acto les basta con decir que es autoritario (autoritär). Ahora bien, «autoridad» significa, respecto de lo que en el artículo se trata, tanto como supraordenación de una voluntad ajena sobre la nuestra, con lo cual ella presupone la subordinación. Dado que ambas palabras resultan malsonantes para la parte subordinada, surge la cuestión de si acaso no existirá un medio para proceder de otro modo, o sea, si acaso, bajo las relaciones sociales contemporáneas, se podría reclamar la existencia de otro Estado social en el que tal autoridad ya no tuviese sentido alguno y, consecuentemente, desapareciese. Se sigue, a partir de aquí, la respuesta de Engels.

Cuando se observan las relaciones económicas e industriales que forman el basamento de la sociedad civil contemporánea se constata el cada vez mayor reemplazo de la actividad aislada por la actividad combinada de los individuos. En lugar de los pequeños talleres de otro tiempo han aparecido grandes fábricas en las cuales cientos de trabajadores vigilan complicadas máquinas, así como las carretas han dejado su lugar al ferrocarril y los botes a los grandes barcos. La máquina pone progresivamente bajo su dominio a la economía; lenta pero ineluctablemente reemplaza a los pequeños propietarios por grandes capitalistas, que cultivan grandes

${ }^{6}$ Tomamos la importante cita de Anti-Dühring (K. MarX y F. EngELs, Werke, t. 20, Berlin, Dietz, 1978, p. 262). Las mismas ideas las reitera Engels en Die Entwicklung des Sozialismus von der Utopie zur Wissenschaft, Berlin, 1891 (cfr. t. 19, p. 224, de la edición de Dietz).

7 «Von der Autorität», en K. Marx y F. Engels, Werke, t. 18, Berlin, Dietz, 1976, pp. 305-308. Se trata, que sepamos, de un texto que no ha sido traducido al castellano; de ahí el espacio que le damos en estas páginas. 
extensiones con ayuda del trabajo asalariado. Por doquier avanza la actividad combinada, la complicación de procesos recíprocamente dependientes. Ahora bien, quien dice actividad combinada dice organización. Y el autor inquiere: ¿es posible la organización (Organisation) sin autoridad?

Engels plantea entonces la cuestión sirviéndose de un ejemplo, a saber, la situación que se produciría como resultado de una revolución socialista. Tal revolución ha desplazado a los capitalistas, bajo cuya autoridad (Autorität) era dirigida (lenken) hasta ese momento la producción y circulación de las riquezas. Al hacerlo, la propiedad de los medios de producción ha pasado a manos de los trabajadores. En ese caso, pregunta Engels a los «antiautoritarios», ¿desaparecería la autoridad o sólo cambiaría de forma? A partir de aquí comienza una respuesta basada en una serie de ejemplos más concretos, extraídos de la actividad de diversos grupos u organizaciones consagrados a una tarea común. En el caso de una hilandería se dan numerosas y diversas operaciones: se necesita un ingeniero para las máquinas, mecánicos para reparaciones, trabajadores no cualificados que transporten lo producido. Pero esos numerosos trabajadores de toda edad, sexo y condición deben comenzar y terminar su tarea en un tiempo prefijado, y esta exigencia no tiene en cuenta las pretensiones de la autonomía individual (literalmente: «le importa un bledo la autonomía individual», dice Engels). Por otra parte, surgen múltiples cuestiones — modo de producción, distribución del material, etc.- que deben ser solucionadas rápidamente si no se quiere que la producción entera se detenga. Ahora bien, sea que tales cuestiones se resuelvan a partir de la decisión de un delegado, sea que se decidan por acuerdo mayoritario, siempre la voluntad de uno se hallará subordinada a la de otro. En cualquier caso, concluye Engels, las cuestiones que inevitablemente suscita la vida de una organización deben ser autoritariamente resueltas ${ }^{8}$.

Análoga situación ofrece el caso de un ferrocarril. También allí la cooperación (Kooperation) de una pluralidad de individuos aparece como absolutamente necesaria; cooperación que debe hacerse efectiva respecto del cumplimiento de horarios determinados, so pena de que acaezcan sucesos desafortunados. Y también aquí la primera condición de la empresa colectiva consiste en una voluntad dominante, sea que tal voluntad esté representada por un delegado individual o por un comité al cual le esté

${ }^{8}$ ENGELS —en consonancia con la teoría de la evolución social por él preconizadavincula la necesidad de la autoridad con las consecuencias del dominio técnico de la naturaleza: «ésta, en efecto, se venga sometiendo al hombre a la subordinación sin la cual organización productiva alguna existiría», dice en el texto comentado. 
encomendada la ejecución de los acuerdos de la mayoría. Sea su forma la que fuere, nos las habemos con la autoridad. Pero la necesidad de la autoridad, y con competencia espacial, surge con mayor patencia que en ningún otro ámbito en el caso de un navío en alta mar. A bordo de él, ante la proximidad del peligro, la vida de todos depende de la presta obediencia a una voluntad absoluta.

Engels remata su razonamiento afirmando que nadie ha escapado a la pregnancia de estos argumentos, y agrega con sorna que nada cambia las cosas — como algunos hacen- el negarse a llamar «autoridad» a la función sobre la que se discute y referirse a ella como una misión (Auftrag), ya que la disputa no gira en torno de nombres, sino de realidades. En síntesis, se ha visto, continúa Engels, que una autoridad, bajo la forma que fuere, acompañada de la subordinación, constituyen elementos que se nos imponen, junto con las condiciones materiales de producción, independientemente de la clase de organización de que se trate. Por otra parte, las tendencias económicas modernas van extendiendo progresivamente el campo de la autoridad.

De ahí que resulte absurdo tomar el principio de autoridad como absolutamente malo y el de autonomía como absolutamente bueno. Autoridad y autonomía son realidades relativas cuyo ámbito de concreción varía de acuerdo con la evolución social. Los autonomistas (se refiere a los anarquistas) son ciegos para los hechos que hacen necesaria a la cosa y se lanzan contra la palabra. Deberían, por el contrario, contentarse con tronar contra la autoridad política. En efecto, todos los socialistas coinciden en que el Estado político, y con él la autoridad política, habrán de desaparecer como consecuencia de la revolución proletaria. Ahora bien, eso significa que la autoridad perderá su carácter político, es decir, de instrumento clasista de opresión, mas no que desaparecerán las funciones públicas mismas. Ellas, remata Engels, se transformarán en funciones administrativas, es decir, necesarias para velar por los intereses sociales.

En conclusión cabe afirmar que, según Engels, son los intereses (= fines) de la comunidad los que exigen la existencia de una función imperativa que ordene las conductas de los miembros del grupo en pos de esos fines.

Despojada de las accidentales incrustaciones confesionales o ideológicas, la esencia de la posición común a Tomás de Aquino y a Engels (al Engels de este texto, por lo menos) se erige como una explícita objeción contra las doctrinas que, desde los sofistas a Weber, pasando por el agustinismo medieval y Hobbes, han reducido el poder político a la coacción y 
a la violencia organizadas. Tal posición viene a decir que la existencia del poder de régimen se funda en la necesidad absoluta de una instancia de dirección en la sociedad. Esto, que vale para toda sociedad stricto sensu, adquiere a fortiori especial relevancia en el específico caso de la sociedad política, cuya proverbial complejidad pone aún más de manifiesto la necesidad de la ordenación imperativa al fin común.

Así pues, y como primera conclusión crítica: la identificación de la autoridad mundial con un poder tuitivo y represivo universal centralizado presupone - o por lo menos trasunta - la falsa concepción de que la esencia (función primaria) de la autoridad política estriba en la organización de la coacción.

\section{b) La implicación de la seguridad en todos los ámbitos de la vida política}

Ahora bien —y más allá del error teórico de atribuirle una función primariamente coactiva-, se plantea la cuestión de si acaso la existencia de un poder mundial reducido a la preservación coactiva de la seguridad podría cumplir una función de vigilancia sobre las comunidades políticas sin ejercer injerencia activa en los asuntos domésticos de éstas.

Dejemos por un momento de lado el ejercicio directo de la fuerza por el poder mundial, es decir, el control violento de las guerras; este tema nos ocupará en especial más adelante. Consideremos ahora la preservación del valor seguridad a través de la prevención. Ante todo, parece difícil que tal instancia no decidiese controlar el gasto y el equipamiento militares, y ejercer supervisión sobre todo lo relativo a defensa y seguridad (exterior e interior). Pero, además, el poder mundial supervisaría la investigación y la aplicación tecnológica de los desarrollos científicos en todas aquellas áreas que considerase vinculadas o vinculables con el uso bélico. Relevantes iniciativas científico-tecnológicas de avanzada quedarían sometidas, inevitablemente, al contralor discrecional del poder mundial. En otro orden, este poder también reclamaría para sí el derecho a juzgar qué régimen político, y, además, qué personas o grupos, desde el gobierno, podrían representar un riesgo potencial para la seguridad interestatal; por ende, impondría su veto sobre movimientos o personas o equipos en el ejercicio del poder o con aspiraciones a desempeñarlo. Ya en el ámbito de la política penal, el poder mundial se hallaría particularmente interesado en la persecución y la sanción punitiva de ciertos delitos y de toda actividad que considerase atentatorios a la seguridad global. 
La lista de esferas de la vida comunitaria en la que la preservación de la seguridad pudiera hallarse o juzgarse involucrada no acaba aquí. Hemos mencionado algunos ejemplos de entre las múltiples posibles hipótesis en que el poder decisorio supremo se consideraría facultado para intervenir en la vida interna de una comunidad política, afectando áreas clave del libre - y lícito- desenvolvimiento de un pueblo políticamente organizado. No hay ámbito de la vida política, sea el científico-educativo, el jurídico o el político, que resulte imposible de vincular con la seguridad. Tal constatación - dicho sea de paso- demuestra hasta qué punto el fin y el objeto de todo poder político excede la mera coacción y reafirma la tesis ya expuesta sobre su verdadera función primaria. En efecto, la coacción no es sino un medio ordenado a la tutela y la promoción de verdaderos (o falsos) bienes humanos participables. Y es la dirección de las conductas consociadas a tales bienes comunes la que constituye la función prioritaria de cualquier potestad.

El último señalamiento sobre la insuficiencia del valor seguridad como fin del poder social y político explica que la preservación de la seguridad necesariamente comprometa dimensiones más altas de la vida comunitaria de las que - por la naturaleza de las cosas - la seguridad depende. Precisamente en esa línea, en este punto $b$ ) nos interesaba subrayar que una potestad coactiva suprema necesariamente interferiría en la independencia interna de las comunidades políticas (de ésas a las que debe proteger de sí mismas). Y, en tal medida, comprometería su status de comunidades políticas en tanto políticas (i. e., dueñas de decidir sobre sus propios asuntos -incluidos sus propios asuntos domésticos-).

Entonces, y como segunda conclusión crítica: la existencia de un poder mundial coactivo reduciría a los Estados, de jure y de facto, a una condición con rasgos más bien asimilables a la de circunscripciones políticoadministrativas descentralizadas.

Y más nos inclinamos a esta alternativa que a la de Estados miembros de un Estado federal, en razón del carácter artificial que asumiría un poder mundial supraordenado respecto de pueblos tan diversos. Un Estado federal, por ser a menudo el fruto de una integración política en la que interviene la voluntad, la tradición y la idiosincrasia de los pueblos concurrentes, habitualmente guarda correspondencia con el perfil propio de esos pueblos - cuya diversidad concreta es resguardada por la unidad política conformada- Porque esa misma unidad, reiteramos, es el resultado de causas conmensuradas a los grupos y a las naciones que intervienen. Así, por un lado, los Estados federales de América han asumido de modo espontá- 
neo formas de régimen republicanas, coaptadas a su tradición, y por otro lado, la federación alemana del II Imperio se constituyó adoptando y respetando las formas de régimen que cada Estado de la confederación germánica había asumido históricamente, fueran éstas principados o repúblicas. Por su parte, los Estados de tradición unitaria suponen una cierta homogeneidad social y nacional, y tal modo de régimen, como forma de una comunidad histórica particular, no podría ser tachado de ilegítimo. En cambio, un poder último y supremo erigido súbitamente sobre pueblos tan diversos difícilmente dejaría de revestir carácter artificial por su ajenidad con las comunidades a las que rige y sobre cuyo concreto modo de vida social decide. Ahora bien, lo artificial, así entendido, se contrapone a lo natural (en su acepción de aquello fundado en la esencia de la cosa o, ya como natura individui, en su acepción de aquello coaptado a la peculiaridad del sujeto, individual o colectivo - que aquí es un pueblo políticamente organizado-). Y lo contrario a lo natural es, en sentido radical, violento?.

\section{c) La autoridad mundial y la evitación de la guerra}

Uno de los leitmotive de la preconización de la necesidad de un poder mundial es la instauración de la paz entre los Estados; en otros términos, el control de las hostilidades interestatales en orden a la desaparición de las guerras.

Dentro de las concepciones en las que la asimilación de la política a la organización de la fuerza es explícita, como en el caso de Kant, propugnar un Estado mundial equivale a y se resuelve en la instauración de un poder mundial coactivo ${ }^{10}$. Es en Kant en quien se expresa paradigmáticamente el reclamo de que los Estados abandonen el estado de naturaleza y depongan su salvaje libertad en aras de la constitución de una Unión de Estados (Völkerbund), que sería el término a quo para la creación final de un Estado mundial (Völkerstaat $)^{11}$.

\footnotetext{
9 Cfr. Aristóteles, Ethica Nicomachea, ed. de Bywater, Oxford, Oxford University Press, 1110b, pp. 15-17. Allí dice ARISTÓTELES que lo violento (biaion) reside fuera del agente; si entendemos que al agente (moral) su naturaleza teleológicamente ordenada no le es exterior, sino intrínseca, podemos afirmar que violento es aquello que se opone a lo natural, en tanto lo natural es constitutivo formal del hombre.

${ }^{10}$ Sobre este tema en KANT hemos hecho una síntesis en S. R. CASTAÑo, «Individualismo y Estado mundial. Esbozo de las premisas del modelo kantiano», Rivista Internazionale di Filosofia del Diritto, serie V, año LXXVIII, núm. 3, pp. 283-300.

${ }^{11}$ Cfr. I. Kant, Zum ewigen Frieden, en W. WeIschedel (ed.), Werke in zehn Bänden,
} 
La pregunta es: ¿ese poder, con las tipicidades que, de acuerdo con lo visto, podemos suponer en él, evitaría las guerras, entendidas como los enfrentamientos hostiles y sangrientos en los que uno o más pueblos o grupos se oponen recurriendo a las armas? Vamos a proponer, a propósito de esta cuestión verdaderamente crítica y de enorme relevancia, un argumento basado en las consideraciones de uno de los más agudos teóricos del Estado del siglo xx: Carl Schmitt ${ }^{12}$.

Schmitt analiza la situación internacional posterior a la Primera Guerra Mundial (creación de la Sociedad de Naciones, pactos de Locarno, Briand-Kellog...), con su tendencia a la federalización y su explícita condena del uso de la fuerza en las relaciones internacionales bajo la figura del anatema a la «guerra de agresión» (en la que tendía a subsumirse toda guerra ofensiva). Su atención se halla focalizada en la interesantísima cuestión de la criminalización del enemigo, un rasgo espiritual y jurídico-político que Schmitt detecta en el escenario internacional contemporáneo. Dado que no podemos adentrarnos en este apasionante tema, vamos concretamente a lo que nos atañe aquí. Sinteticemos sus argumentos.

La alteración de la estructura del orden internacional y su transformación en una entidad de carácter federal (i. e., su transformación de orden interdependiente en orden integrado) implica la desaparición del concepto de guerra (mas no de la guerra real). En efecto, si las supremas decisiones emanan de la conducción de la federación habrá, por un lado, sanciones y ejecuciones jurídicas contra los miembros estatales de la federación que incurran en faltas al ordenamiento común a todos, y por otro, rebeliones y delitos (por parte de esos miembros), pasibles de una acción punitiva (por antonomasia, el extermino a través del bombardeo aéreo). Aparece la imposibilidad, concluye Schmitt, de emplear un único concepto para ambos tipos de acción militar, análogamente a como no puede subsumirse bajo un mismo concepto la acción del policía y la del malhechor. En realidad tampoco habrá, sensu stricto, guerras, es decir, contiendas entre enemigos que se reconocen idéntico status político y jurídico y se tratan recípro-

Darmstadt, 1983, t. IX: «Zweiter Definitivartikel zum ewigen Frieden», pp. 208-213. La idea ya había sido preludiada en Idee zu einer allgemeinen Geschichte in weltbürgerlicher Absicht (op. cit., t. IX, Satz. 7, pp. 41-45) y reaparece en la Rechtslebre (op. cit., t. VII, pp. 474 y ss.).

${ }_{12}$ Huelga decir que estos señalamientos schmittianos no serán usados como argumentos de autoridad, sino para introducir el diálogo y direccionar la investigación. A SCHMITT, un autor polémico en cuyas ideas se debe hacer metódicamente una criba doctrinal, se le deben con todo proverbiales aciertos en algunos de sus posicionamientos teóricos. En lo que sigue nos servimos de nuestro artículo «La criminalización del enemigo en Carl Schmitt», Empresas Políticas, año IX, núm. 14-15, pp. 151-158. 
camente como tales. Para el Derecho tradicional la guerra se libra entre sujetos primarios del Derecho internacional público, esencialmente distintos de un gangster o de un pirata. De ahí que la guerra, dice Schmitt, invista una particular dignidad; dignidad irradiada por los actores mismos que la protagonizan (las comunidades políticas). Pero, contrapone Schmitt, «la teoría actual [posterior a la Primera y a la Segunda Guerra Mundial] de la guerra justa tiende precisamente a la discriminación del adversario que libra la guerra injusta. La propia guerra se convierte en delito. El agresor es declarado criminal en el sentido más absoluto de esta palabra: es declarado fuera de la ley como un pirata ${ }^{13}$. En efecto, un nuevo orden del mundo con pretensiones ecuménicas tenderá a tratar a quien lo resista como a un enemigo injusto, a quien ya no se le reconocen títulos jurídicos para la contienda — ni paridad de status - . Por ello, afirma también Schmitt, «antes de que el concepto de guerra sea eliminado y se pase de una guerra estatal a una guerra civil internacional deben primero ser eliminados los pueblos estatalmente organizados» ${ }^{14}$. Bajo esos presupuestos jurídicos e ideológicos impugnados por Schmitt — que no son, dicho sea de paso y sin detenernos ahora a demostrarlo, los de la doctrina clásica y escolástica-, esta idea de guerra justa acarrea necesariamente la intensificación de la violencia y de la enemistad hacia quienes resultan un obstáculo para la unidad universal. A partir de la entrada de Estados Unidos en el primer conflicto mundial, con su pretensión de determinar lo justo y lo injusto mas allá de sus fronteras, la distinción entre guerra justa y guerra injusta, que desemboca en la discriminación entre beligerante justo y beligerante injusto, se hará una «más profunda y más aguda, cada vez más "total" distinción de amigo y enemigo», que ya no dejará lugar para la neutralidad ${ }^{15}$. Esta argumenta-

${ }_{13}$ El nomos de la tierra en el derecho de gentes del Ius Publicum Europaeum, trad. de D. Schilling, Madrid, CEC, 1979, p. 128.

${ }^{14}$ C. Sснмітт, Die Wendung zum diskriminierenden Kriegsbegriff, 2. ${ }^{a}$ ed , Berlin, Duncker \& Humblot, 1988 (reed. de la de 1938), p. 48.

${ }^{15} \mathrm{Ibid}$., pp. 47-53. SсHмiтT analizó las motivaciones político-culturales de la oscilación norteamericana entre aislamiento e imperialismo discriminatorio en Cambio de estructura del derecho internacional, conferencia pronunciada en Madrid, Instituto de Estudios Políticos (IEP), 1943. Allí expresaba: «Cuando el autoaislamiento frente al resto del mundo se convierte en discriminación de ese mundo, la guerra se torna acción punitiva y expiatoria que discrimina al adversario como criminal» (p. 25). Michael WALzER detecta un ejemplo ilustrativo de ese nuevo espíritu en la actitud de Eisenhower cuando se negó a recibir al coronel general von Arnim, comandante vencido del Afrikakorps, quien, de acuerdo con usos seculares todavía vigentes, deseaba presentar sus respetos al vencedor. Así interpreta WALzER la conducta del militar norteamericano y sus posteriores explicaciones de ese hecho: «[E]n ese sentido, no importa que von Arnim haya peleado bien; su crimen era haber peleado. Por lo mismo, el modo de combatir del general Eisenhower no importa. Contra la conspiración 
ción de Schmitt, preñada de realismo y en general animada por principios de racionalidad práctica cuya validez resulta difícil de desconocer, encuentra un antecedente en San Agustín. El yugo militar de un extenso imperio, que además impone su lengua a los pueblos sometidos, no elimina la guerra como tal — señala el Hiponense-, sino que sólo da origen a otras formas de violencia colectiva (como la guerra civil), sin merma - antes al contrario- de las catástrofes que la guerra desata ${ }^{16}$. De hecho, San Agustín ya había señalado la conveniencia de que los hombres se organizaran a lo largo del orbe en un pluriverso de comunidades políticas ${ }^{17}$.

En conclusión: frente a instancias políticas y jurídicas supranacionales con títulos para decidir sobre la justicia de una guerra entre Estados y, sobre todo, frente a poderes que enarbolen la pretensión de monopolizar el uso legítimo de la fuerza internacional, ya no habrá más guerras. ¿Por qué? Porque, de un lado, habrá intervenciones y ejecuciones por parte del poder mundial, único representante del orden y de la justicia, y, de otro, habrá insurrecciones, piratería internacional, terrorismo, etc. Es decir, que desaparecerá el nombre de «guerra». Lo cual no significará la desaparición de la violencia colectiva organizada. Antes al contrario: porque al horror de la realidad de la guerra se sumará el hecho de que los enemigos ya no se respetarán, sino que se tratarán como criminales —o, peor aún, como réprobos y malditos-

\section{La protección de derechos fundamentales (persona humana, grupos sociales) como materia de necesaria interpretación del ápice del poder}

Se ha propuesto que la autoridad mundial debería velar por la vigencia de los derechos humanos ${ }^{18}$. Analicemos las consecuencias de esta hipótesis.

Podría concederse que, en general, algunos de los tratados internacionales sobre derechos humanos reflejan derechos fundamentales de la persona humana. Decimos esto midiendo nuestras palabras, porque en el caso de cada instrumento y de cada derecho o grupo de derechos proclamados

del mal lo esencial era vencer. El espíritu caballeresco pierde su razón de ser y ya no existen límites "fuera de la fuerza misma"» (cfr. M. WALZER, Just and Unjust Wars, trad. francés de S. Chambon y A. Wicke, Berlin-Paris, 1999, p. 77).

${ }_{16}$ Cfr. San Agustin, De civitate Dei, XIX, VII (t. II, Madrid, BAC, 1978, p. 573).

${ }_{17}$ Cfr. ibid., IV, XV (t. I, Madrid, BAC, 1977, p. 250).

18 Paradigmática al respecto es la posición de Pacem in Terris (cfr. núm. 139). 
cabría hacer una ponderada valoración que aquilatara su valor de auténtica justicia. Dicho esto, concedamos el supuesto normal de una declaración de derechos no sólo aceptada por el Estado que suscribe el tratado correspondiente, sino, más aún, objetivamente aceptable en sus estipulaciones. Pues bien, la doctrina reconoce - pacífica y, sobre todo, razonablemente- que esos instrumentos internacionales tienen jerarquía constitucional «en las condiciones de su vigencia», esto es, con inclusión de las reservas y declaraciones interpretativas que la comunidad política agrega, especificando cómo (o sea, con qué concretos alcances, límites, contenidos, etc.) entiende la validez del derecho proclamado o reconocido ${ }^{19}$. Todo lo cual significa que el concretísimo modo de reconocimiento de derechos fundamentales, aun tratándose de verdaderos derechos subjetivos naturales, es materia pasible de interpretación normativa, y no sólo por parte de los poderes constituidos (por ejemplo, en el nivel de la aplicación judicial), sino ya desde el plano constitucional mismo. Hemos tocado aquí un problema de enorme trascendencia al que a veces no se le presta la debida atención. El ordenamiento jurídico, con su ápice constitucional, custodia un modo inveterado de la convivencia que se concreta de acuerdo con unos usos y tradiciones constitutivas. Éstas, por su parte, se anclan en los consensos existencialmente aceptados por los grupos de una comunidad, y por ésta como un todo a través de su propia historia. Hay un modo concreto de entender el dominio sobre las cosas y, por tanto, el derecho de propiedad y los intercambios comerciales; un modo concreto de entender las relaciones entre los sexos y, por tanto, los usos matrimoniales; un modo concreto de concebir el orden familiar y, por tanto, el régimen sucesorio y los usos educativos. Se trata - repárese bien en esto- de usos particulares históricamente sedimentados que tomarán, en sus núcleos fundamentales, forma jurídico-positiva. Pues aunque los contenidos mismos reconozcan naturaleza de derecho natural (primario o secundario), la vigencia misma de tales principios se debe a su positivación por los usos comunitarios. En suma, puede existir un abanico diversísimo de realizaciones, en

19 Respecto de esta cuestión en general, pero a propósito de los tratados de derechos humanos que la República Argentina ha incorporado a su constitución, cfr. G. BIDART CAMPOS, Tratado elemental de Derecho constitucional argentino, t. VI, Buenos Aires, Ediar, 1995, p. 557; J. Vanossi y A. Dalla Via, Régimen constitucional de los tratados, Buenos Aires, Abeledo-Perrot, 2000, p. 322; G. BADENI, «El caso "Simón" y la supremacía constitucional», La Ley, supl. de Derecho penal, julio 2005, y Academia Nacional de Derecho, «Dictamen acerca de los tratados y la supremacía constitucional», 2005. Fuera de la doctrina argentina y en el mismo sentido véase J. A. CARRILlo SALCEDO, Soberanía de los Estados y derechos humanos en Derecho internacional contemporáneo, Madrid, Tecnos, 1995, p. 67.

Foro, Nueva época, vol. 18, núm. 1 (2015): 27-60 
principio lícitas, del concreto modo de existencia social, económica, jurídica y, por tanto, política. De ahí que cualquier declaración de derechos, por la naturaleza de las cosas, deba ser recepcionada en una cierta - $\mathrm{O}$ sea, determinada, peculiar, concreta- comunidad humana sobre la que se asienta un orden político y constitucional ${ }^{20}$. El ordenamiento constitucional argentino «post 1994» es acabado ejemplo de ello — tanto más cuanto que ostenta una excepcional «penetrabilidad» (sic), como ha dicho un constitucionalista español ${ }^{21}$-: los tratados internacionales que se integran en la Constitución lo hacen «en las condiciones de su vigencia [...] no derogan artículo alguno de la Primera Parte de esta Constitución y deben entenderse complementarios de los derechos y garantías por ella reconocidos» (véase Constitución Nacional, art. 75, inc. 22). Y lo afirmado aquí como un principio vale, téngase esto muy en cuenta, aun en el supuesto de que los derechos a ser reconocidos fueran verdaderos derechos humanos universales; es decir, aun sin suponer que la comunidad política deba defenderse de la imposición de pretensiones no universalizables —o incluso de antivalores-.

Para ilustrar lo afirmado vayan algunos ejemplos de derechos subjetivos naturales que no por universales dejan de exigir una concreción particular. Así, piénsese en el derecho natural a la participación política, que admite múltiples realizaciones análogas a las formas de régimen; en los posibles distintos derechos políticos, matrimoniales e infantiles, que sin embargo no niegan la igualdad esencial de los sexos; en el derecho a la libertad de conciencia, que se manifiesta en el ámbito civil o público (regulada sea como tolerancia, sea como «libertad religiosa»); en los derechos a la libertad y a la dignidad de la persona frente a los varios modos en principio lícitos de la sanción penal; en las diversas variantes del instituto de la propiedad, rectas en tanto no vulneren ni su sentido humano ni su necesaria ordenación al bien común; etc.

Capítulo aparte — que sólo mencionamos- lo conforma el grave tema de la tipificación de ciertas conductas delictivas de índole política, como algunos de los supuestos de los llamados crimenes de lesa bumanidad: así,

${ }^{20}$ Para la relación entre democracia, tradición política, constitución y legitimidad del poder nos permitimos remitir a S. R. CASTAÑo, «Legitimidad de origen y consenso. Síntesis y precisiones desde los principios del orden político», en M. ${ }^{a}$ I. GARRIDO y J. EsPINOZA DE Los Monteros (eds.), Paradigmas y desafíos del constitucionalismo democrático, Granada, Comares, 2014.

${ }^{21}$ A.-C. Pereira Menaut, Rule of Law o Estado de Derecho, Madrid, Marcial Pons, 2003, pp. 62 y 114. 
el de la «persecución sistemática contra la población civil», figura penal de riesgosa determinación para una instancia jurisdiccional extraña al ámbito de los hechos bajo proceso ${ }^{22}$, pues si bien puede reflejar casos extremos de auténtica caza de personas o grupos independientemente de la comisión por ellos de acción dolosa alguna (caso del genocidio - en el sentido estricto, i. e., étnico del término- de Rwanda), semejante «persecución sistemática» no es extensible sin flagrante abuso, por ejemplo, al combate por parte de los órganos del Estado de una guerra revolucionaria (nos referimos al ejercicio de la función tuitiva del Estado, no a modos ilegales o ilegítimos de represión) ${ }^{23}$.

Decidir políticamente sobre sus propios asuntos implica, en sustancia, decidir sobre ese patrimonio histórico-espiritual. Una declaración de derechos que aspire a ser jurídicamente operativa no podrá evitar su concreta recepción, adopción, reglamentación e interpretación desde una comunidad determinada. Luego, si la autoridad mundial se propone tutelar los derechos humanos deberá necesariamente erigirse en la última alzada e instancia de contralor de las decisiones de los poderes supremos de cada comunidad respecto del modo de realización y ejercicio de esos derechos. Porque la concreción efectiva de esos derechos supone su invisceración normativa en el plexo de relaciones sociales de una comunidad histórica determinada, desde el nivel constitucional hasta los fallos judiciales y los actos administrativos. Ahora bien, la asunción de tales facultades — constituyentes y constituidas $-{ }^{24}$ por la autoridad mundial

${ }^{22}$ Hemos discutido alrededor de estas polémicas cuestiones en «La imprescriptibilidad de ciertos delitos como valor jurídico absoluto. Una reflexión desde el derecho natural clásico», en Anuario de Derechos Humanos, vol. 8, Madrid, Universidad Complutense de Madrid, 2007.

${ }^{23}$ Con la faz jurisdiccional del poder político se vincula precisamente una de las propuestas de poder mundial planteadas contemporáneamente. Se trata de la ya citada de Hans KeLSEN, quien propugnaba la instauración de un tribunal internacional de jurisdicción obligatoria que fuera creando paulatinamente las condiciones necesarias para la conformación de un poder ejecutivo centralizado (cfr. H. KelSEN, La paz por medio del derecho, op. cit., pp. 48-54). Esta versión de la idea de poder mundial constituye, ha dicho Max SCHELER, la marca típica de la corriente por él llamada «pacifismo jurídico o de Derecho», nacido del derecho natural radical moderno y cuyo objetivo final es reemplazar la ultima ratio de los Estados por un tribunal supremo que decida sus conflictos mediante un rígido sistema normativo. Dado que el Derecho habla a través de un juez, ese tribunal supranacional sería el Derecho viviente (cfr. M. SCHeler, Zur Idee des ewigens Friedens und der Pazifismus, en M. SCHeler, Gesammelte Werke, vol. 13, Schriften aus dem Nachlaß, t. IV, Bonn, Bouvier, pp. 98 y 108).

${ }^{24}$ Un ejemplo claro de hasta qué punto la pretensión de tutela de los derechos humanos acarrea la asunción de facultades constituyentes y constituidas la brinda el fallo «Olmedo Bustos y otros vs. Chile (La última tentación de Cristo)», de la Corte Interamericana de Derechos Humanos (5 de febrero de 2001), en el que ésta declara que «el Estado [chileno] debe modificar su ordenamiento jurídico interno» (véase XII, 4, del fallo; se refiere allí al art. 19, 
implicaría la desaparición de las comunidades políticas en tanto tales (y, como consecuencia, pondría en riesgo el modo peculiar de realización humana de que cada una es portadora). Veamos por qué espigando la teoría de la soberanía del Estado expuesta por Hermann Heller en La soberanía. La obra de este gran teórico del Estado, sin duda el mayor del siglo xx junto con Carl Schmitt, reviste un significativo interés para el abordaje de la naturaleza del Derecho positivo y abre la vía para el esclarecimiento del quicio de la justificación de la vida política y de la legitimidad de ejercicio del poder del Estado. El poder del Estado, sostiene Heller, es soberano en tanto posee la capacidad y la obligación de definir definitiva y eficazmente en todo conflicto que altere la cooperación social-territorial. Tal poder es creador del Derecho positivo, pues el poder político tiende por naturaleza a expresarse y regir en forma jurídica; se trata de un poder jurídicamente organizado que, siendo siempre legal, también necesita ser legítimo. Ahora bien, si, por un lado, la existencia del Derecho depende de la acción de una unidad decisoria soberana; por otro, la naturaleza de la validez jurídica (positiva) resulta diversa de la validez lógica en la medida en que se funda en los datos históricos, culturales, sociales, humanos en suma, fuera de los cuales se torna ilusoria. Así pues, las normas positivas deben no sólo su existencia, sino también su validez, a la acción individualizadora de un poder decisorio concreta y culturalmente situado, que determina las normas en función de un talante comunitario y no a partir de una idea abstracta, como lo pretende el racionalismo kelseniano. Por último, y sin perjuicio de todo ello, Heller sostiene que la justificación última del Estado y de su poder se funda en la facultad de aplicar y ejecutar los principios jurídicos fundamentales (Rechtsgrundsätze) (en parte «apriorísticos», es decir, no culturales, sino naturales) que se hallan en la base de todo derecho que pueda ser reivindicado realmente como tal ${ }^{25}$.

núm. 12, de la Constitución Política del Estado), así como derogar el Decreto Ley 679, de 1 de octubre de 1974 — dejándose desde luego sin efecto la correspondiente sentencia de la Corte Suprema de Justicia de Chile que prohibía la exhibición de la película en cuestión-, por colisionar todos ellos con el art. 13 de la Convención Americana de Derechos Humanos sobre el derecho a la libertad de pensamiento y de expresión. Cabe observar que la Corte Interamericana de Derechos Humanos ha enarbolado la pretensión del «control de convencionalidad», según la cual los órganos jurisdiccionales se hallarían en la obligación de actuar ex officio para adecuar todo el orden normativo de la comunidad política con la interpretación que de la Convención hace esa Corte, en tanto su intérprete última — vid. Almonacid Arellano vs. Chile (2006), 124; Gelman vs. Uruguay (2011), 193-.

${ }^{25}$ Cfr. H. Heller, Die Souveränität, caps. II, «Dominación y orden», y III, «Soberanía 
Pero no cabe finalizar este punto sin volver a lo ya dicho sobre el concreto modo de vida colectiva que cada orden político supone, preserva, desarrolla y transmite. Es necesario retener - como un principio éticojurídico fundamental — que el señorío sobre lo propio asocia su peraltado valor a la preservación de un estilo peculiar de perfección humana, el cual, junto con el de los demás pueblos del orbe, constituye la armónica perfección de la especie humana como un todo. Y es ese orden plural universal el que quedaría comprometido frente a un poder mundial, pues la renuncia al derecho a la libre disposición sobre su propia vida social, económica, cultural y jurídica («derecho soberano») implicaría, a la postre, la tendencia a la licuación y el aplanamiento del perfil propio de la comunidad en provecho de un solo modo de realización de la vida humana - abstracto, ajeno y centralizado- ${ }^{26}$.

Precisamente vale la pena señalar, en parágrafo aparte, una de las manifestaciones idiosincráticas propias de cada comunidad de más elevado rango humano, y que antes y con mayor seguridad resultaría preterida por un poder mundial: nos referimos a la forma política.

y positividad», Berlin, De Gruyter, 1927, pp. $92-96$ y 118-121, e íD., Staatslebre, Tübingen, Mohr Siebeck, 1983, p. 254.

${ }^{26}$ Afirmamos esto sin perjuicio de reconocer que algunas propuestas de institución de una autoridad mundial han propugnado el respeto de las peculiaridades constitutivas de cada pueblo a ella sujeto. Lo cual se echa de ver en especial en aquellas formulaciones medievales de cuño aristotélico como las de Dante. Este gran espíritu, al delinear la naturaleza de la monarquía temporal universal, había señalado la necesidad de que el poder supremo diera a cada pueblo una legislación coaptada a su perfil propio. Dice en Monarchia (I, XIV): «[H]abent namque nationes, regna et civitates intra se proprietates, quas legibus differentibus regulari oportet: est enim lex regula directiva vite». Pero la continuación del texto del propio autor, creemos, avala nuestra posición acerca de la inevitable deriva hacia la uniformización espiritual que un poder único acarrea: «[S]ed sic intelligendum est: ut bumanum genus secundum sua comunia, que omnibus competunt, ab eo [scl., Monarcha] regatur et comuni regula gubernetur ad pacem. Quam quidem regulam sive legem particulares principes ab eo recipere debent, tanquam intellectus practicus ad conclusionem operativam recipit maiorem propositionem ab intellectu speculativo, et sub illa particularem, que proprie sua est, assummit et particulariter ad operationem concludit. Et hoc non solum possibile est uni, sed necesse est ab uno procedere, ut omnis confusio de principiis universalibus auferatur» [D. Alighieri, Monarchia, en P. G. Ricci (ed.), Mondadori, Società Dantesca Italiana, 1965, pp. 164-165]. Nótese que del hecho de que los principios especulativos y prácticos sean comunes no se sigue que deba haber una potestad común. En efecto, la afirmación de una ley natural universal no implica la existencia de una sociedad política mundial ni, por ende, la necesidad de una autoridad terrena suprema común. Sobre esta cuestión clave remitimos a nuestra crítica al monismo jurídico jusnaturalista de Alfred VerdROss en S. R. CASTAÑo, El Estado como realidad permanente, Buenos Aires, La Ley, 2003 y 2005, pp. 175-182. Se halla una síntesis de este tema en Dante en B. LANDRY, L'idée de Chrétienté chez les scolastiques du XIII ${ }^{\text {ime }}$ siècle, Paris, PUF, 1948, pp. 179-195.

Foro, Nueva época, vol. 18, núm. 1 (2015): 27-60 


\section{Los criterios de legitimidad concreta monopolizados por una sola posición}

Ha sido un tópico doctrinal distintivo de la tradición aristotélica la tesis de que el poder político funda su legitimidad en la ordenación al bien común político, y la de que diversas formas de gobierno (monarquía, aristocracia y república, con sus cuasi innumerables variantes particulares) pueden ser, por tanto, legítimas en tanto y cuanto miren al fin recto ${ }^{27}$. Esas formas deberán consonar, por otra parte, con la peculiar e intransferible circunstancia histórica, cultural, nacional, étnico-nacional, geográfica, etc., de cada comunidad concreta en un momento de su vida colectiva. Recurriendo a las categorías normativas de la tradición del iusnaturalismo aristotélico clásico cabe decir con precisión que la existencia de la potestad de régimen es de Derecho natural, mientras que las formas de régimen (tanto las «formas de Estado» cuanto las «formas de gobierno») son de Derecho positivo. Esta posición rechaza los ideologismos que identifican la legitimidad con una forma política particular, sea la monarquía de derecho divino - como ocurrió en los siglos XVI-XIX—, sea — como ha ocurrido sobre todo a partir de la segunda mitad del siglo xx- la democracia, no entendida de modo genérico, sino en la peculiar forma del régimen democrático-representativo del constitucionalismo liberal, fundado en la soberanía del pueblo y hoy estructurado en el molde del «Estado de partidos» ${ }^{28}$, cuya forma se ve hoy a menudo identificada con la legitimidad política ut sic.

Pues bien, la existencia de un poder mundial acarrearía inexorablemente la imposición paulatina de una forma de régimen —asumida como la sola legítima o deseable - sobre pueblos diversos con tradiciones, idiosincrasias, culturas y disposiciones también diversas. Pueblos, nótese, que no habrían renunciado a su status de comunidades políticas, con lo cual tampoco habrían renunciado a llevar adelante su propio modo de existencia política a partir de su talante constitutivo. Todo lo cual se vería desconocido por la preeminencia de un poder que sería árbitro del Derecho positivo a nivel mundial y, en esa medida, árbitro de los criterios concretos de legitimidad. No sorprende que cuando, en las últimas décadas, se preconizó nuevamente la necesidad de una autoridad mundial, uno de sus

27 Aristóteles, Politica, en Ross (ed.), Oxford, Oxford University Press, 1279 a 17-31.

${ }_{28}$ Para un desarrollo de esta última noción véase M. García-Pelayo, El Estado de partidos, Madrid, Alianza, 1986. 
corifeos no haya trepidado en sostener que ésta «promoverá la constitución de un buen régimen político basado sobre la división de poderes» (es decir, en el molde del constitucionalismo liberal iluminista propio de las revoluciones del siglo XVIII), pues, según el rasero ideológico del autor, «la idea cristiana de comunidad internacional implica, sí, la transformación de las naciones asociadas en Estados democráticos» ${ }^{29}$. Se trataría de la puesta en práctica del art. XVI de la Declaración de los Derechos del Hombre y del Ciudadano, según el cual toda sociedad cuyo ordenamiento prescinda de las exigencias del modelo liberal carece de constitución; pretensión ésta que vale diacrónica y sincrónicamente (o sea, que antes o fuera del liberalismo occidental no hay legitimidad política) ${ }^{30}$.

Pongamos un ejemplo en el que se manifieste cuál es el derecho que inviste a una comunidad política, es decir, no integrada en una comunidad mayor, a la hora de preservar su orden histórico constitutivo. Para ello echaremos mano de un supuesto hipotético que no se atiene a determinaciones positivas (como las del Tratado de Viena), sino que intenta ir a «la naturaleza de las cosas». Nos referimos a un derecho cuyo libre despliegue puede operarse con perfecta licitud (más allá de las eventuales dificultades que su ejercicio pueda acarrear a la comunidad en cuestión) en el orden internacional. En esta hipótesis - para mejor inteligir el sentido del principio - no se debe acudir a una contraposición axionormativa entre una pretensión injusta (la del instrumento internacional) y otra justa (la de la comunidad en cuyos asuntos se interviene). Supongamos, pues, que aparece un conflicto o colisión entre el legítimo orden interno de una comunidad política —orden jurídicamente expresado por sus leyes fundamentales (Constitución) - y un instrumento jurídico internacional también legítimo que vincula pacticiamente a esa comunidad política con otras comunidades del orbe (Tratado). Pues bien, si una pretensión o interpretación de ese acuerdo internacional, sin contradecir principios jurídicos fundamentales, con todo sí contrariase intereses legítimos de una comunidad política signataria por vulnerar su identidad histórica constitutiva, esta comunidad política, ¿tendría derecho a determinar que lo justo concreto, en ese caso, pasa por hacer prevalecer su orden constitucional por sobre la pretensión fundada en el instrumento intercomunitario? Dicho de otro modo,

${ }^{29}$ L. Pereña Vicente, «Comunidad y autoridad supranacional», en Comentarios a la Pacem in Terris, Madrid, BAC, 1963, p. 564.

${ }^{30}$ Hemos tratado el tema en clave histórica y sistemática en S. R. CASTAÑo, Legalidad y legitimidad en el Estado democrático-representativo, Madrid-Buenos Aires, Marcial Pons, prólogo de Dalmacio Negro (de próxima aparición).

Foro, Nueva época, vol. 18, núm. 1 (2015): 27-60 
si cupiera la convicción a las potestades de una comunidad política, de buena fe, de que el bien común sufriría desmedro (grave) por la aplicación de un tratado - incluso en un caso en que ni la forma ni el fondo de esta pretensión contradijesen per se la justicia objetiva-, esas potestades ¿tendrían derecho a rehusarse a aplicar la disposición internacional? Estimamos que sí tiene derecho la comunidad política, y que en ese derecho estriba el signo — no la esencia — de que esa comunidad es política (autárquica) sensu stricto. Si objetivamente no lo tuviera sería porque tal comunidad sería parte (políticamente integrada) en un todo político mayor, o estaría en vías de serlo. $Y$ entonces la disposición ya no sería internacional, sino de orden político interno (actual o incoado). Pues bien, frente a un poder mundial concentrado, tal derecho natural a la independencia, con todo lo que esa independencia preserva, quedaría deónticamente cuestionado y, sobre todo, sería fácticamente inviable.

\section{La «subsidiariedad» internacional y su ilícita analogía con el orden intraestatal}

\section{a) Subsidiariedad, totalidad y politicidad}

En ocasiones se ha recurrido al principio de subsidiariedad para explicar el funcionamiento de una instancia decisoria - política, jurídica o económica- supraordenada respecto de las potestades propias de las comunidades políticas. Se ha dicho, pivotando sobre tal principio, que las decisiones del poder mundial (supremo) no invadirían las materias reservadas para sí por las comunidades políticas, sino que sólo ejercerían una acción supletoria allí donde las comunidades no bastasen para atender los fines a los que se ordenan ${ }^{31}$.

Ahora bien, el principio de subsidiariedad, de suyo, regula las relaciones entre la comunidad política y los grupos sociales infrapolíticos, y aquí se trata de las relaciones entre una autoridad mundial y comunidades políticas. La pregunta clave es: la proporción de las relaciones, en ambos casos, ¿es idéntica? Si es así ¿se aplica entonces el principio de subsidiariedad con analogía de proporcionalidad propia en ambos casos? Intentemos responder esta cuestión a veces mal comprendida.

${ }^{31}$ Así, por ejemplo, en el caso de la idea de autoridad mundial propugnada por Pacem in Terris (cfr. núms. 140-141). 
De acuerdo con el principio de subsidiariedad hay un poder superior propio de una sociedad superior cuyo fin es, precisamente, superior a los fines de los cuerpos intermedios. El poder de esa sociedad superior está obligado a apoyar a las sociedades menores en la consecución de sus propios fines. Se trata de un principio de derecho natural, por cuanto debe reconocerse que se halla fundado en las exigencias objetivas del orden social en tanto orden humano ${ }^{32}$. Sin embargo, ante una necesidad de bien común, o ante una grave transgresión a los principios jurídicos fundamentales en el seno de un grupo, la sociedad superior podría juzgar lícito, decidir y ejecutar el suplantar a esas sociedades menores y tomar a su cargo sus funciones. La tradición aristotélica interpretará tal subordinación en los siguientes términos: el principio de subsidiariedad resuelve su sentido y legitimidad últimos en el principio de totalidad o de primacía del bien común que es perseguido por la comunidad superior.

Ahora bien, ¿qué ocurriría en el caso de una autoridad mundial? Si verdaderamente se verificase la situación propia de la subsidiariedad, entonces sería ilusorio seguir hablando de comunidades políticas, en la medida en que éstas estarían sujetas a una potestad superior. En efecto, si existiera una autoridad mundial, poder llamado a tutelar valores globales impostergables, pretendiendo decidir por sí misma cuándo y en qué ámbitos y hasta qué límite intervendrá en la esfera propia de comunidades subordinadas, entonces habría que aceptar que esas comunidades ya no serían independientes, pues en realidad ellas serían, de facto e incoativamente de jure, miembros de una comunidad política superior que las englobaría y decidiría en última instancia. Y si la existencia del Estado mundial no se reconociese abiertamente, de todas maneras en este caso las comunidades políticas habrían dejado de ser tales para adquirir los derechos y deberes propios - y, por ende, la naturaleza propia- de un grupo infrapolítico. Pero si las comunidades políticas reclamasen para sí la independencia, la sola existencia y acción de una autoridad mundial configuraría una situación ilegítima —además de potencial o actualmente conflictiva—, porque los Estados verían inevitablemente desconocidos sus derechos básicos de jurisdicción sobre lo propio por las decisiones del poder mundial.

Luego, no habiéndose verificado jamás el supuesto de la existencia legítima y pacífica de un Estado mundial consensuado por y coaptado a todos

32 Sobre el principio de subsidiariedad como uno de los ejes del recto orden político cfr. E. Soто KLoss, Derecho administrativo. Temas fundamentales, Santiago de Chile, LexisNexis, 2009, esp. pp. 67 y ss.

Foro, Nueva época, vol. 18, núm. 1 (2015): 27-60 
los pueblos del orbe, el planteamiento de una autoridad mundial fundada en el principio de subsidiariedad resulta altamente aporético y conflictivo, en la medida en que ese principio regula las relaciones entre un poder de jure superior al de otros grupos — grupos, remárquese, infrapolíticos (i. e., infraestatales) - L La vigencia de los derechos a la autodeterminación comunitaria frente un poder reconocido como supremo quedaría por principio comprometida. En efecto, si «soberano es quien decide en estado de excepción» entonces también habría que decir que en estado de excepción quien decide es el soberano ${ }^{33}$. Y quien juzgue cuándo hay estado de excepción y determine cuáles son sus competencias en una circunstancia dada respecto de la intervención en un Estado será, necesariamente, el poder supremo. Si éste, además, monopolizara la fuerza militar internacional -o dispusiera de un peso incontrastable en ese plano-, por hallarse encargado de preservar la paz y el orden (es decir, investido de la misión de vigilar al mundo), entonces la libertad de las comunidades se tornaría lisa y llanamente ilusoria, en razón de que semejante poder no sólo decidiría ad libitum, sino que actuaría sin oposición posible. Despojadas así de sus facultades soberanas sobre sus propios asuntos y de los medios fácticos para tutelarlos, las comunidades políticas dejarían de ser tales y se verían reducidas a la condición de circunscripciones administrativas o, en el mejor de los casos, de Estados miembros de un Estado federal (sobre ambas alternativas véase supra).

\section{b) Los principios que se inducen y se comprueban a partir de un fallo}

Toda dilucidación en el plano de los principios del orden práctico, en la medida en que sea correctamente planteada, se relaciona esencialmente con la manifestación empírica de los fenómenos sociales, jurídicos y políticos, y es capaz de explicarlos. Nosotros hemos avanzado hacia una dilucidación política principial respecto del problema de un poder subsidiario mundial. Veamos si tal dilucidación es coincidente con el plano empírico, es decir, si alcanza a explicar y justificar los hechos históricos. Para ello recurriremos a un leading case contemporáneo, el fallo «Maastricht» del Tribunal Constitucional Alemán (12 de octubre de 1993) ${ }^{34}$.

33 C. Schmitr, Politische Theologie, München-Leipzig, Duncker \& Humblot, 1934, p. 11. Como se ve, aceptamos la fórmula de SснмiтT respecto de lo que sería una función propia de la soberanía, mas no como expresión de la esencia de esa potestad suprema.

${ }^{34}$ Bundesverfassungsgericht (compilación on line), t. 89, pp. 155 y ss. Nos servimos en 
En ese fallo se dedican varios pasajes precisamente al principio de subsidiariedad, dado que la subsidiariedad constituye uno de los tres fundamentos en los que se basa la estructura política y jurídica de la Unión Europea. El principio de subsidiariedad —establece el Tribunal — se halla contractualmente normado y faculta a obrar a los órganos de la Unión respecto de aquellos cometidos que, siendo parte de los objetivos políticos de los Estados miembros, sin embargo, escapan a los medios de consecución que éstos puedan arbitrar individualmente [C.II.3.c)]. Pero, por otro lado, se agrega que la subsidiariedad vigente en la Unión Europea tampoco pierde de vista la preservación de la identidad nacional de los miembros y la evitación de la erosión de sus atribuciones, en la medida en que «las facultades de los Estados particulares son la regla, las de la comunidad la excepción» (aunque — se aclara - siga siendo siempre necesaria la atenta vigilancia de los poderes de los Estados miembros) [C.II.2.a)]. He aquí por qué nos interesa el caso de la Unión Europea y las consideraciones de «Maastricht»: porque en la Unión existen órganos supranacionales y rige el principio de subsidiariedad, pero en un entramado jurídicamente normado por unidades políticas que reclaman para sí y ejercen efectivamente sus derechos soberanos. Es en este escenario político, pues, donde podremos constatar qué forma de subsidiariedad es posible y legítima cuando las comunidades junto a las que actúa un poder subsidiario son comunidades políticas sensu stricto.

La Unión carece de la Kompetenz-Kompetenz (es decir, facultades que podrían ampliarse ad libitum por los órganos de la Unión: se trataría de una facultad soberana en cabeza de los órganos comunitarios), sostiene el Tribunal. En efecto, las funciones de los órganos comunitarios —aquí se introduce un argumento clave del fallo- obedecen al principio de la autorización particular (Einzelermächtigung) y se hallan limitadas a competencias específicas. De donde se sigue que toda extensión de funciones o facultades depende de una reforma o adición al tratado, la cual, a su vez, dependerá de la aprobación de cada Estado miembro. Por ello el tratado crea una unión de Estados cuya identidad nacional reconoce y no un Estado europeo $(\mathrm{C})^{35}$.

lo que sigue de S. R. CASTAÑo, Lecturas críticas..., op. cit., pp. 105 y ss., y de ÍD., «La secuencia ontológica del orden político como presupuesto de la politicidad del Derecho y de la legitimación del poder. A propósito del fallo "Maastricht"», Criterio y Conducta, núm. 3 (2008), pp. 15-34.

35 Sobre la Einzelermächtigung, II.2.a): «Todos los órganos de la Unión reciben sus competencias y funciones de una autorización particular normada por el tratado (art. E); sólo dentro de los límites de las funciones asignadas y de los fines normados por el tratado puede la Unión ejercer sus poderes» [art. 3.b) EGV]. 
El desempeño del poder supremo en una unión de Estados se funda en la autorización que los miembros soberanos hacen recaer en los órganos comunitarios; son las comunidades políticas sensu stricto las que actúan en última instancia en el ámbito interestatal y, así, comandan el proceso de integración, continúa el Tribunal. Un poder comunitario de tal naturaleza, a saber, basado en la voluntad política de varios pueblos asociados, presupone que el órgano a cargo de su ejercicio representa a los gobiernos de los Estados miembros. Por ello, para que sea posible la actuación de los órganos europeos, debe quedar claramente establecido qué alcance y medida de la extensión del ejercicio de derechos supremos han sido aprobadas por el legislador alemán ${ }^{36}$. Caso contrario, se habría producido una «autorización general», es decir, una cesión definitiva de facultades supremas, la cual invalidaría — por inconstitucional— la acción de los órganos europeos [C.I.2.c) y C.I.3]. Si éstos pretendieran extralimitarse en sus atribuciones e ir más allá de lo establecido por el tratado suscrito por Alemania, tales actos carecería de valor jurídico en el ámbito soberano alemán (C.3 ${ }^{37}$. La República Federal de Alemania, agrega el Tribunal más adelante, es miembro de una unión de Estados cuyo poder deriva de los Estados miembros. En el ámbito soberano de Alemania, ese poder sólo puede tener efectos vinculantes merced a la voluntad conforme del ordenamiento jurídico alemán expresada en la ley de adhesión al tratado. Tratado del que Alemania — recuerda el Tribunal— es uno de los «señores» [C.II.1.a) y C.II.b). $6^{38}$ ].

Observemos que el principio de subsidiariedad aplicado al ámbito de una unión de Estados no es ni idéntico ni análogo con analogía de proporcionalidad propia respecto del mismo principio regulando las relaciones entre el Estado y los cuerpos infrapolíticos. En realidad, el poder subsidiario actúa, en este caso, no como última instancia de imperio normativo y decisorio, sino sujeto a las estipulaciones restrictivas que los Estados le han impuesto. Es decir, la «carga decisoria» respecto de cómo y cuándo obrar — que en el ámbito del Estado es de resorte prudencial exclusivo de los órganos de éste y excluye la participación del cuerpo intermedio- aquí

${ }^{36}$ Más adelante, en C.II.3.b), el Tribunal explicita que el tratado no sólo determina los fines de los órganos europeos, sino que también delimita objetivamente sus funciones y facultades en el nivel de los medios.

${ }^{37}$ Cfr. II.2.d).2.

38 En el último paso se dice: «Cada una de esas modificaciones o extensiones presupone, sin embargo, que los Estados miembros se adhieren de acuerdo con sus precedentes constitucionales». 
aparece fuertemente amortiguada $-\mathrm{O}$ tal vez esencialmente transmutada- por la condición estatal de los grupos cuya acción complementa. En definitiva, el factor decisorio último continúa en manos del Estado, aunque aquí se halle «bajo» el órgano de la Unión, ya que son los Estados miembros los que han normado previa y restrictivamente los ámbitos y procedimientos de acción del órgano supletorio ${ }^{39}$.

Luego - $\mathrm{y}$ sin adentrarnos más en los contornos peculiares de la Unión Europea, lo cual no corresponde a nuestra intención aquí- cabe establecer una conclusión. Un poder subsidiario cuyas atribuciones se hallen específica, restrictiva y taxativamente autorizadas por las comunidades que lo han fundado mediante un tratado multilateral -el cual implica un acto revocable de voluntad de parte de la comunidad (que así se obliga ante otros pares en una relación de coordinación)—, este poder subsidiario, decimos, sí puede ser compatible con la existencia de comunidades políticas que no han renunciado a su status de tales, esto es, de Estados independientes (y esto aún bajo el supuesto de la conformación de una Unión de Estados - un contexto político en principio no favorable para la conservación de los fueros soberanos de los Estados miembros, en la medida en que es dable que ya manifieste un pondus a la integración en una sola unidad política-). Es que, en rigor - e incluso en esos casos de fuerte interdependencia - ya no se trata de un poder subsidiario en sentido propio, sino de una delegación específica, limitada y, sobre todo, revocable de competencias.

Ahora bien, a diferencia de las autorizaciones en principio particulares a un órgano jurisdiccional — como en el caso de la Corte Interamerica-

39 «El tratado no ha determinado una Kompetenz-Kompetenz — sigue diciendo el Tribunal-, y no lo ha hecho porque no ha identificado la voluntad concorde de las partes con la existencia de un sujeto jurídico independiente (selbständiges) que deba ser considerado titular de competencias» [C.II.2.b).1]. Ahora bien, si la Unión no constituye un nuevo sujeto portador por sí mismo de competencias originarias es porque su entidad (socialmente categorizada) no alcanza el rango de una comunidad política: sus relaciones fundamentales, agregamos nosotros, lo son aún las de coordinación, por ello sus órganos no pueden hallarse investidos de supremacía jurídica. En palabras del Tribunal, «el tratado no crea a la Unión como un sujeto jurídico independiente, sino un "nombre" (Bezeichnung) para el obrar común de los Estados miembros» [C.II.2.b).2]. Cabría acotar por nuestra parte, interpretando el contenido lógico-ontológico de semejante proposición, que la Unión sólo tiene el nombre de una Gemeinschaft; es decir, es comunidad en sentido impropio. Las auténticas comunidades lo son los Estados. En efecto, dirá también el tribunal, «los sujetos sociales que "insuflan vida" a la Unión son las diversas comunidades políticas signatarias del tratado» [C.II.2.d).2.1]. Hasta aquí la posición del Tribunal respecto de cuál sea la naturaleza política de la Unión, posición que él juzga es compartida tanto por los órganos europeos como por los demás Estados miembros [C.II.b).6].

Foro, Nueva época, vol. 18, núm. 1 (2015): 27-60 
na de Derechos Humanos respecto de Hispanoamérica y Brasil, o como la Corte de Luxemburgo respecto de los Estados de la Unión Europea ${ }^{40}$-, la creación de una autoridad mundial «subsidiaria» con la misión de proteger los derechos humanos, la justicia universal, la paz y el orden, etc. -lo cual implica facultades decisorias últimas y supremo poder constituyente-, resulta inconciliable con la existencia de comunidades independientes sujetas a ese poder y deja intactos los problemas, situaciones de ilegitimidad y fuentes de conflictos que se han detectado supra.

\section{La estabilidad económica como inescindible de todas las dimensiones de la vida política y jurídica contenidas en el bien común}

No nos extenderemos en este punto por mor de brevedad y porque las principales tomas de posición críticas referidas a la hipótesis de una autoridad económica mundial se infieren análogamente a partir de lo hasta aquí dicho $^{41}$. Baste con considerar que, para la comunidad independiente, la renuncia a las decisiones últimas sobre la conducción de su economía equivale sin más a declinar la responsabilidad sobre el destino de su propia vida política. Áreas tales como la política monetaria, el concreto alcance de la intervención estatal en la economía, el endeudamiento público, la regulación del sistema financiero, el régimen impositivo $-\mathrm{O}$, ya en un plano que combina lo socio-poblacional, las leyes inmigratorias-, por sólo mencionar

${ }^{40}$ En cuyo seno las decisiones más relevantes de los poderes jurisdiccionales no han desmentido el fondo de «Maastrich». Así, en el fallo «Lisboa» (2009), el Bundesverfassungsgericht sostiene que la Ley Fundamental no sólo presupone, sino que también garantiza la estatalidad soberana alemana (Abs. núm. 216). Se trataría de un principio rígido (o invariable, o irrevocable —unabänderlich_-) del ordenamiento constitucional alemán. Sobre el tema cfr. los agudos análisis de D. MurswIEK, «Der Grundsatz der souveränen Staatlichkeit als unabänderliches Verfassungsprinzip», en H. C. Kraus y H. A. WolfF (eds.), Souveränitätsprobleme der Neuzeit, Berlin, Duncker \& Humblot, 2010, pp. 95-148.

${ }^{41}$ No mera hipótesis, en realidad. Existió una propuesta del Pontificio Consejo de Justicia y Paz de 25 de octubre de 2011, bajo la forma de una nota titulada «Por una reforma del sistema financiero y monetario internacional en la prospectiva de una autoridad pública con competencia universal». Comienza así: «[T]oda persona individualmente, toda comunidad de personas, es partícipe y responsable de la promoción del bien común. Fieles a su vocación de naturaleza ética y religiosa, las comunidades de creyentes deben en primer lugar preguntarse si los medios de los que dispone la familia humana para la realización del bien común mundial son los más adecuados». Sobre esta apelación al bien común internacional, al que se ordenarían directamente las personas y los grupos (principio reiterado en el documento), volveremos en las conclusiones. 
algunas pocas, asumen tal incidencia en el conjunto de la existencia social y comprometen tan a fondo dimensiones sustanciales del bien común (o sea, del destino común) que la sujeción en esas materias a una instancia decisoria externa despojaría a la comunidad de su condición de política. Aun la acción de poderes económicos supraestatales que surgen de tratados multilaterales o de uniones de Estados resulta ilegítima si pretende valer como última decisión en las disposiciones económicas de un Estado, en tanto éste no haya renunciado a su status de tal integrándose como parte de un nuevo todo político mayor. Y repárese en que lo ilegítimo, por ser desordenado, genera desorden y resulta actual o potencialmente conflictivo y disgregador. Las economías pequeñas y medianas de Europa, sujetas al Diktat del sistema económico-financiero de la Unión Europea, brindan un buen ejemplo del efecto deletéreo - presente y futuro- que este factor de ilegitimidad puede acarrear en todos los planos de la vida social.

Por tanto, se echa de ver el lastre ideológico de las soluciones antipolíticas que aspiran a «superar al Estado», sin distinguir la ganga del Estado moderno de la necesidad natural de la comunidad política. Es así como a veces se propugnan formas diversas de mundialismo que absorban el orden de comunidades independientes. Tal rechazo del pluriverso de Estados, más allá de sus pretensiones aparentes, termina resultando preterición de la política concreta - la cual comporta dimensión humana y legitimidad histórica y, asimismo, implica comunidad organizada investida de independencia temporal- $\mathrm{y}$, a la postre, tal rechazo concluye en la eliminación de la política a secas, a la que se aspira a subsumir bajo el imperio de los valores tecnocráticos y económicos ${ }^{42}$.

\section{UN INTENTO DE RESOLUCIÓN EN LOS PRINCIPIOS}

A lo argumentado hasta aquí cabría oponerle toda la gama de posiciones que postulan la subordinación del Derecho público interno al Derecho internacional. Paradigmática y precursora en nuestro tiempo ha sido en ese sentido la doctrina del gran filósofo e internacionalista Alfred Verdross ${ }^{43}$. Asumiendo tal presupuesto, podría suponerse que una autoridad política mundial no colisionaría con el orden jurídico internacional, sino que cul-

\footnotetext{
42 Ejemplo de esto último es el planteamiento de Á. D’Ors, Una introducción al estudio del Derecho, Pamplona, Rialp, 1987, esp. pp. 156 y ss.

${ }^{43}$ Cfr., por todos, A. Verdross, «Le fondement du droit international», RCADI, t. 16, pp. 247-323.
}

Foro, Nueva época, vol. 18, núm. 1 (2015): 27-60 
minaría y perfeccionaría un orden objetivo que establece la sujeción de los Estados al Derecho internacional público.

A esta altura de nuestras consideraciones no resulta oportuno plantear la demostración del error que reside: 1) en confundir la primacía axionormativa de los principios generales del Derecho, o ley natural, con la primacía del Derecho internacional positivo sobre el orden político interno, y, además, 2) en identificar la vigencia de un orden jurídico internacional (interestatal) con la existencia de una sociedad política mundial ${ }^{44}$. Con todo, será pertinente, en primer lugar, aducir la crítica que Hermann Heller enderezó contra los juridicismos mundialistas que, en franca eclosión ya tras la Primera Guerra Mundial, desconocían los fueros del Estado a partir del previo desconocimiento de la naturaleza de la realidad política. Y tras ello - ya como conclusión que intente resolver el problema en sus fundamentos últimos- convendrá esbozar cuál es el principio que explica la naturaleza no social, en sentido estricto, del orden internacional y, por ende, y en análoga medida, la ilegitimidad de un poder mundial.

\section{Heller: el Estado y su potestad soberana como causa $y$ presupuesto del Derecho internacional}

La concepción del Estado y de su soberanía adquiere asimismo axial relevancia en Heller para el perfilamiento de las relaciones de la comunidad política con el orden internacional. Heller se opone a «los enemigos del dogma de la soberanía», entre los que se contaban importantes internacionalistas de la posguerra, el gobierno de Wilson y Kelsen, su gran adversario teórico (en quienes Heller advierte sutilmente las concomitancias antipolíticas con el marxismo). Frente a todo orden jurídico positivo el Estado permanece como elemento determinante, y dado que en el orden internacional no hay un Estado mundial, sino pluralidad de Estados, serán éstos quienes libremente determinen (positivicen) el Derecho internacional público. Por ello «[e]l acto de sometimiento de un Estado a una norma cualquiera del Derecho internacional tiene que ser construida jurídicamente como una libre decisión voluntaria», remata el catedrático de Frankfurt ${ }^{45}$.

En la misma línea, es de destacar la coincidencia de fondo que muestra Hermann Heller, partiendo de otros principios pero con la mirada puesta

${ }^{44}$ Desarrollamos esa refutación en S. R. CASTAÑo, El Estado como realidad..., op. cit., pp. 175 y ss.

${ }^{45}$ H. Heller, Die Souveränität, op. cit., p. 124. 
en la realidad objetiva, con las conclusiones de las posiciones clásicas sobre el carácter de presupuesto que reviste la existencia de las comunidades políticas respecto del Derecho internacional ${ }^{46}$. Según esa tesis helleriana clave para la inteligencia del orden internacional, el Estado nace y perdura como una cierta realidad social, y existe como sociedad política — con la legitimidad que le es propia- aun cuando no entable relaciones jurídico-internacionales de ninguna especie. Luego, en lo tocante a la sociedad política, el carácter constitutivo del reconocimiento internacional sólo operará respecto de su categorización como sujeto del Derecho internacional público, mas no de su carácter de Estado en tanto tal. En efecto, en cuanto a la existencia en acto de la unidad política, el reconocimiento del Derecho internacional será meramente declarativo ${ }^{47}$. Ahora bien, si el Estado no aparece ni pervive por decisión del Derecho internacional, por ende tampoco su potestad supondrá una delegación o distribución de funciones emanada de tal orden normativo. Es decir, que la potestad de la sociedad política resulta específicamente diversa de una competencia jurídica. Este último juicio aparece como un corolario obligado de la aceptación de la existencia del Estado como dato primario del orden internacional (= interestatal). Afirma así Heller rotundamente una conclusión central respecto de la naturaleza y valor del Estado, en crucial oposición con las ideas de los impugnadores de la realidad y de la independencia de la comunidad política - y, a fortio$r i$, de la política misma-: «[L]a identificación de competencia y soberanía es la expresión de una idea que hace del Estado una ficción, para poder postular la ficción de la civitas maxima» ${ }^{48}$.

\section{La raíz ontológica y axiológica de la ilegitimidad política de una autoridad mundial}

\section{a) El bien común internacional y los derechos del hombre}

No nos proponemos en este lugar hacer un desarrollo de la noción de bien común social y político y de sus diversas formas análogas. Daremos

${ }^{46}$ Nos remitimos aquí a S. R. CASTAÑO, «Souveräne Staatsgewalt nach der Lehre Hermann Hellers und potestas superiorem non recognoscens bei Vitoria und Suárez im Vergleich», Archiv für Rechts- und Sozialphilosopbie, Band 100, Heft 1, pp. 77-93.

${ }^{47}$ Cfr. H. Heller, Die Souveränität, op. cit., cap. VII, «Soberanía del Estado y subjetividad jurídica internacional».

${ }^{48}$ Ibid., p. 160. 
por supuesta la concepción clásica de bien común y sólo intentaremos determinar cuál es la naturaleza propia del bien común internacional ${ }^{49}$. Para ello delinearemos las respectivas consideraciones de Louis Lachance en El Derecho y los derechos del hombre ${ }^{50}$, con cuyas posiciones en esta cuestión coincidimos en lo sustancial.

Como la misma noción de bien, también la noción de bien común es análoga. Así, se habla de un bien común familiar, de un bien común político y de un bien común internacional. Se plantea la dificultad, muy debatida y de aristas complejas, de la determinación del bien común internacional, fundamentalmente de si consiste en un bien común idéntico al de las comunidades políticas, sólo que de mayor extensión; en otros términos, la cuestión de si acaso el bien común internacional es, él también, un bien común político. Lachance sostiene que el bien común internacional carece de dos notas esenciales del bien común político, a saber, la de organicidad y la de historicidad. El fin político, como el fin familiar (y el de las instituciones educativas), comprende a todo el hombre, es decir, no atiende a una dimensión actualizable de la persona, sino a ella en su integridad corpóreo-espiritual. Pero, a diferencia del fin familiar, el fin político es capaz de perfeccionar de modo más cabal y profundo al hombre. Se estructura a partir de un orden jerárquico de funciones e instituciones fundado en el orden de las necesidades humanas, que generan múltiples modos de colaboración entre individuos y grupos. El bien humano asequible a la comunidad política supone, pues, un denso entramado de relaciones, plural y complejo como el conjunto de actividades que los hombres cumplen al perseguir el orden de fines a que los impele su mismo ser. Por el contrario, el bien común internacional consiste en valores que revisten la naturaleza de medios para el despliegue de cada comunidad autárquica, a saber, la seguridad (como remoción de los obstáculos que permiten los intercambios) y la paz (ésta entendida también en sentido positivo no como ausencia de conflictos, sino como llamado a la colaboración entre los sujetos

49 Para una fundamentación del concepto clásico y realista de bien común político cfr., por ejemplo, G. Soaje Ramos, «Sobre la politicidad del Derecho», y J. M. ${ }^{a}$ Medrano, «Tomar en serio el bien común», ambos en S. R. CASTAÑo y E. Soto Kloss (eds.), El derecho natural en la realidad social y jurídica, Santiago de Chile, Academia de Derecho UST, 2005, y la mejor obra de conjunto que se ha elaborado sobre este tema, A. M. QuinTAs, Analisi del bene comune, Roma, Bulzoni, 1979 y 1988. Circula, por razones no científicas, la concepción y definición del bien común como «conjunto de condiciones». Sobre esta idea nos permitimos remitir a S. R. CASTAÑ̃, «¿Es el bien común un conjunto de condiciones?», L'Ircocervo, núm. 1 (2011), pp. 1-19.

${ }^{50}$ Utilizamos la trad. cast. de L. Hornos, Madrid, Rialp, 1979, esp. pp. 229 y ss. 
interdependientes que componen el orden internacional). Por otra parte, además de orgánico, el bien político es histórico. Esto significa que los fines humanos que convocan a la pólis —en particular su ápice, los bienes espirituales - se hallan signados por una historia concreta que los perfila y, en esa medida, los torna amables (i.e., capaces de atraer como fin) para los grupos y las naciones nucleadas dentro de ese común horizonte de sentido. No son, pues, bienes cualesquiera (abstractos, desencarnados) los que mueven a los hombres moldeados por un destino y una tradición, sino aquellos que, por hallarse coaptados a su segunda naturaleza colectiva cultural, han causado la convivencia y han cristalizado relaciones de integración perdurables. Pero, por el contrario - agregamos nosotros-, el bien común internacional carece de tal proximidad axiológica; por ello no puede causar la projimidad comunitaria que sí causa el bien de la pólis, el cual a la completitud le une la concretidad.

En síntesis, el bien común internacional no es un bien común en el sentido propio de la noción; antes bien, cabría categorizarlo como un conjunto de condiciones que posibilita la perfección de las comunidades políticas que componen el orden internacional ${ }^{51}$.

\section{b) La ilegitimidad de una subordinación sin integración. $Y$ un cuestionamiento final}

La conclusión que se sigue a partir de la categorización del bien común internacional como forma impropia de bien común social se impone con toda necesidad: ese bien público no puede ser causa de relaciones de integración plenas que constituyan una comunidad política. Y ello en razón de que no es un bien de la misma naturaleza del bien común que causa la existencia de las comunidades políticas del orbe. Luego, si no puede ser fin de una comunidad política, tampoco puede ser fin del órgano autoritativo de conducción que arraiga en el Estado (es decir, del órgano que supone la realidad de la comunidad política). En otros términos, en el plano internacional no hay un fin político - y, por ende, una

${ }^{51}$ Hemos desarrollado y utilizado teóricamente estos conceptos en S. R. CASTAÑo, Principios políticos para una teoría de la constitución, cap. II (sobre el bien común como completo y concreto), Buenos Aires, Ábaco de R. Depalma, 2006, y en íd., El Estado como realidad..., caps. II (sobre el bien común internacional como bien común en sentido impropio) y VI (sobre ese bien como conjunto de condiciones para la prosperidad de los Estados independientes). 
sociedad política mundial- que exijan la acción de un poder internacional. Pretender lo contrario sería postular la imposición de relaciones de subordinación formales, estrictas y jurídicas allí donde no existen relaciones de integración en un todo comunitario de naturaleza política. Ahora bien, no bay legítima subordinación - ni durable y pacífica subordinación en el mero plano fáctico- sin previas y fundantes relaciones de integración en una sociedad ${ }^{52}$.

Así pues, el contundente juicio politológico de Hans Morgenthau que citamos al comienzo de este trabajo sobre la inviabilidad de un Estado (como estructura autoritativa) universal en el mundo contemporáneo no constituye sino la constatación empírica de un estado de cosas que se explica a partir de los fundamentos ontológicos y axiológicos de la realidad política. Luego, debe reafirmarse que sin la previa existencia de una sociedad política mundial no sería ni lícita ni tan siquiera posible la instauración de un poder planetario.

Por último, de todo este acápite final (III) se desprende un corolario en el plano de los principios: formalmente hablando, supuesta una hipotética sociedad política mundial, un poder mundial sí podría aspirar a la legitimidad. Sea como fuere, y aunque no se trate más que de una hipótesis, quedaría abierta todavía la cuestión: ¿sería deseable tal situación, que sólo podría fundarse en la nivelación y la homogeneidad de todos los pueblos, tradiciones, talantes y culturas del orbe? Pero la compleja respuesta a tal cuestión ya no forma parte — ni compromete- el presente posicionamiento.

52 Para una demostración fenomenológica, en el plano de la sociología política y jurídica, del carácter fundamental de la relaciones de integración respecto de la existencia y los límites de la asociación estatal, y respecto de la necesidad y el sentido del poder y del derecho, conviene recordar los clásicos planteamientos de G. GURVITCH, «Les formes de la sociabilité», en Essais de sociologie, Paris, Sirey, s.f., e íD., L'idée du droit social. Notion et système du droit social. Histoire doctrinale depuis le XVII ìme siècle jusqu'à la fin du XIX ème siècle, Paris, Sirey, 1932, pp. 9 y ss. 